\title{
DEVELOPMENT AND VALIDATION OF HIGH-PERFORMANCE LIQUID CHROMATOGRAPHY WITH DIODE ARRAY DETECTOR METHOD TO ANALYSIS OF KAEMPFEROL MARKER FROM EXTRACTS OF POINCIANELLA PYRAMIDALIS (TUL) L.P QUEIROZ
}

\author{
AGNA HELIA DE OLIVEIRA, VALMIR GOMES DE SOUZA*, FÁBIO SANTOS DE SOUZA, RUI OLIVEIRA MACEDO
}

Department of Pharmaceutical Sciences, Medicine Development and Assays Unified Laboratories, Federal University of Paraíba, João Pessoa, PB, Brazil. Email: valmirfarmaceutico@gmail.com

Received: 18 July 2017, Revised and Accepted: 24 August 2017

\section{ABSTRACT}

Objective: This study aims to develop the extraction of the marker kaempferol in the fluid extract (FE) and validate an analytical method that monitors the quality of extracts of $P$. pyramidalis.

Methods: The P. pyramidalis leaves were collected and then were dried to milling process. The extracts were drawn up at $20 \%$ weight: Volume (w/v) by maceration, and the extraction system used was hydroethanol solution ratio at 50:50 volume: Volume (v: v). From the hydroalcoholic extract, a method of extracting the kaempferol biomarker was developed and validated by high-performance liquid chromatography coupled with diode array detector. To validate a method, the following parameters were evaluated: Specificity, selectivity, linearity, limit of quantification (LOQ) and detection (LOD), precision, accuracy, robustness, and stability.

Results: The method developed proved to be efficient, as it allowed the analysis of the interferents free marker, with recovery above $90 \%$, linear over the range $1.4-26.6 \mu \mathrm{g} / \mathrm{mL}$, correlation coefficient $\mathrm{R}^{2}=0.999$, and LOD and LOQ 0.07 and $0.22 \mu \mathrm{g} / \mathrm{mL}$, respectively, specificity, precision, accuracy, and robustness.

Conclusion: The extraction methodology of the kaempferol marker was successfully developed interferents free and the validated method by HPLC-DAD represents a useful tool in the quality control of P. pyramidalis herbal medicines.

Keywords: Analytical validation method, Poincianella pyramidalis, Kaempferol, High-performance liquid chromatography with diode array detector. (c) 2017 The Authors. Published by Innovare Academic Sciences Pvt Ltd. This is an open access article under the CC BY license (http://creativecommons. org/licenses/by/4. 0/) DOI: http://dx.doi.org/10.22159/ajpcr.2017.v10i12.21321

\section{INTRODUCTION}

Poincianella pyramidalis (Tul.) L.P QUEIROZ is a species belonging to the genus Poincianella Britton \& Rose to the family Fabaceae, native to northeastern Brazil region, popularly known as "catingueira [1-3]." It is used in folk medicine for the treatment of asthma, bronchitis, diarrhea, gastritis, inflammation, and diabetes $[4,5]$. Several biological activities were tested with this plant, among which we can highlight the antiinflammatory activities, gastroprotective, antioxidant, anthelmintic, and antimicrobial, thus confirming some of its traditional uses [6-8].

Phytochemical investigations showed the presence of terpenes, lignans, tannins, flavonoids, and mainly bioflavonoids $[9,10]$. The kaempferol was isolated from the chloroformic extract of the leaves of $P$. pyramidalis, and several studies have demonstrated pharmacological potential of this compound, especially its anti-inflammatory properties $[2,11]$. Although the phytochemical profiles are complex and the constituents can vary qualitative and quantitatively, it is necessary to establish criteria for the quality of this material, to guarantee the effectiveness and safety of the herbal medicines products [12].

Considering all proven pharmacological activities and their large number of secondary metabolites, this vegetable species represents potential candidate for an herbal medicine product; however, some challenges for the drug development and quality control should be addressed $[13,14]$. One of the most important requirements is an analytical methodology for quality control, since the raw material to finished product and in the case of natural products, appropriate standardization of vegetal drug [13-14].
One of the most challenges to validate analytical methodologies is to ensure the application of methods to monitor the quality since of the raw material up to the finished product and in the case of plant drugs, the proper standardization [15-17]

Chromatographic methodologies have been one of the principal tools in quality control of herbal medicines and widely applied on separation of constituents present in complex matrices. In the development of herbal medicines, it is essential to develop analytical methods that ensure reliable results [18]. Several analytical methodologies have been developed for the identification and quantification of phytochemical markers in plants and their derivatives by high-performance liquid chromatography with diode array detector (HPLC-DAD), but one of the limitations lies in the fact that the most methods do not present a thorough validation [19].

The non-compliance of some validation methods can be checked in the lack of the markers or analytes recovery data and the poor evaluation of matrix effect, demonstrating the challenge in the development of methods that comply with the analytical requirements prioritizing for the sample clean-up interferents free [16]. Special attention should be taken to the preparation of samples of vegetal derivatives involves processes that can result in the degradation of the components of the complex matrix, generating interferents that result in poor selectivity and low reproducibility of the data [20-22]

Samples as biological fluids and plant extracts exhibit a phenomenon known as the matrix effect which corresponds to the influence and interference that all components of the sample in their entirety can exert in the analysis of a component or group of them [23-25]. The interfering 
compounds make it impossible to transpose the method, without right pretreatment of the samples. The great challenge of employing an analytical method to analyze any complex samples for which the method has not been validated lies in the matrix effect that this complex sample may present through interfering substances [26-28].

In the case of $P$. pyramidalis analysis, the chlorophyll and the greases of the leaves may influence the chromatographic run and render the analysis unfeasible. For situations such as these, we use the sample pretreatment techniques that take on the cleaning the sample, making an exhaustive recovery of the analytes, and pre-concentrating the analytes of the sample [29] only the evaluate of analyte recovery can assure that the methodology used in the pretreatment of the sample is efficient for the removal of interferents, and only it can confirm the accuracy of the complex matrix analyte. [30,31].

With the analytical validation of the method, it is possible to complement the standardization of the extract in terms of the marker concentration. This standardization is important not only for quality control of the final product but also is an indispensable tool in preclinical and clinical studies $[32,33]$.

Therefore, the purpose of this work was to validate an analytical method by HPLC-DAD by monitoring the kaempferol marker and to develop an extractive method for the recovery of kaempferol in complex matrices of the P. pyramidalis extract, thus allowing the standardization of the extract as raw material for the production of herbal medicine.

This work is a contribution to broaden the collection of technical and scientific literature about the specie $P$. pyramidalis, providing chromatographic and spectral characterization by HPLC-DAD for the marker kaempferol extracted from the leaves. The novelty of the method lies in kaempferol analytical recovery, free of interferents on complex matrices of $P$. pyramidalis and validation of the parameters, thus satisfying the requirements of the official guides.

\section{METHODS}

\section{Chemicals and solvents}

Kaempferol standard 97\% (Cas 520-18-3)(Sigma Alldrich ${ }^{\circledR}$, Brazil), methanol HPLC grade (Sigma Alldrich ${ }^{\circledR}$, Brazil), orthophosphoric acid (Merk ${ }^{\circledR}$, Germany), Hexano PA ACS (Vetec ${ }^{\circledR}$, Brazil), ethanol 96\% (Toscano ${ }^{\circledR}$, Brazil), and dichloromethane HPLC grade (Vetec ${ }^{\circledR}$, Brazil) were used.

\section{Plant material}

The P. pyramidalis leaves were collected at Maxvida farm, located in Serra branca municipality cariri region in the state of Paraiba in May 2015. The research project with $P$. pyramidalis received authorization from the Ministry of the Environment of Brazil (ICMBio \SISBio \MMA-Brazil) for scientific activities of number: 53346-1. The exsiccate of the plant species was deposited in the Lauro Pires Xavier Herbarium, UFPB Joao Pessoa - Brazil, under number: NC36.

\section{Drying and obtaining powdered plant drug}

The leaves of $P$. pyramidalis were dried in a circulating air oven at a temperature of $40 \pm 2^{\circ} \mathrm{C}$ for 3 days. The dry vegetable drug was submitted to milling process in a vertical rotor mechanical mill. The powdered vegetable drug was packed in a hermetically sealed plastic bag protected from light and moisture.

\section{Standardization of ethanolic extracts}

The standardization of the fluid extract (FE) was established with a proportion of $20 \%$ weight: Volume (w:v) mass of the sprayed vegetable drug and the solvent system. The extraction system used was 50:50 volume: Volume (v:v) hydroethanol solution ratio by maceration.

\section{Chromatographic conditions}

It was used HPLC with DAD (SHIMADZU, Japan), pump 20AT

Degasser DGU20A5, interface CBM 20A, auto-injector SIL 20A, SPD detector M20A, and oven CTO 20A. Control system was carried out by LC Solutions ${ }^{\circledR}$. Stationary phase octadecylsilaneL1: (Gemini nxC-18) particle size: $5 \mu \mathrm{m}$ length: Internal diameter $150 \times 4.6 \mathrm{~mm}$ $\left(\right.$ Phenomenex $\left.^{\circledR}\right)$; precolumn Gemini C-18 $(4 \times 3.0 \mathrm{~mm})\left(\right.$ Phenomenex $\left.^{\circledR}\right)$, mobile phase filtered through a membrane $0.45 \mu \mathrm{m}$ PTFE (Anow ${ }^{\circledR}$, USA) and degassed methanol: $1 \%$ phosphoric acid (47: $53 \%$ ). Flow of the mobile phase: $1.2 \mathrm{~mL} / \mathrm{min}$; oven temperature at $40^{\circ} \mathrm{C}$; monitored wave number $370 \eta \mathrm{m}$; injection volume $20 \mu \mathrm{L}$; chromatographic run time of $30 \mathrm{~min}$.

\section{System suitability testing}

The system suitability test was performed as a procedure to guarantee the reliability of the validation results and to monitor possible variations from changes in the chromatographic equipment. The daily test consisted of 5 runs from the same standard solution of kaempferol with defined concentration. The areas and peak retention times were monitored and the relative standard deviation (RSD) value was at most $1.0 \%$.

\section{Validation of method}

In general, a validated methodology for analyzing an analyte $\mathrm{Y}$ in a matrix A should not be applied directly to analyze an analyte $\mathrm{Z}$ in a matrix B, due to the intrinsic complexity of each matrix [34-35]. But the chromatographic conditions of a given method can be a good reference for the validation of another complex matrix, especially when the analytes or markers belong to the same class of secondary metabolites. Two published papers show validated methods for analyzing quercetin content in two different matrices [36, 28].

In the method validation, the following parameters were evaluated: Specificity, selectivity, linearity, limit of quantification (LOQ) and detection (LOD), precision, accuracy, robustness, and stability. In this work, a method by HPLC-DAD to quantify the kaempferol marker in FE of $P$. pyramidalis was validated as per the ICH guide Q2-R1 [37].

To demonstrate specificity and selectivity of the method, were performed runs in triplicate with samples of $P$. pyramidalis extract, standard solution and blank of mobile phase. The selectivity of method was evaluated by analyze the retention time characteristic of the marker and were recorded the chromatograms of the extract, kaempferol standard, and blank of the mobile phase, in the range of the ultraviolet (UV) spectrum from 200 to $600 \mu \mathrm{m}$ in an interval of $20 \mu \mathrm{m}$.

To evaluate the linearity, calibration curve was prepared with concentrations in the range between $0.4 \mu \mathrm{g} / \mathrm{mL}$ and $7.6 \mu \mathrm{g} / \mathrm{mL}$. This procedure was performed in triplicate for each concentration level.

The determination of the LOQ and LOD was based on the treatment of linearity data by statistical method. The calculation of the LOQ and the LOD was obtained from the deviation of the linear regression and slope of the line.

The repeatability was determined from the injection of 6 samples with kaempferol content close to the mean value $(100 \%)$ of the standard linearity curve. The intermediate precision was determined from the analysis of 6 samples of the extract with analysts and different days. Eighteen chromatographic runs were performed, and the acceptance criterion was $5 \%$ maximum.

The accuracy of the analytical method was assessed by post-addition recovery of the kaempferol marker standard on FE samples. The three levels of concentrations (low, medium, and high) were monitored with values corresponding to $20 \%, 100 \%$, and $180 \%$ against the concentration obtained in the precision. Samples were prepared in triplicate and injections were performed in duplicates for each recovery level, and relative standard deviations and recoverability were assessed.

The determination of the recovery calculation follows the following equation. 
Where:

$$
\operatorname{Rec} \mathrm{X} \%=\frac{[\mathrm{Y}]}{[\mathrm{Z}+\mathrm{W}]} \times 100
$$

Where:

$\mathrm{X}$ : Is the level recovery:

$\mathrm{Y}$ : Is the recovered concentration of kaempferol in the FE;

$\mathrm{Z}$ : Is the initial concentration of kaempferol in FE; and

W: Is concentration of standard substance added.

In the robustness was evaluated variations in the conditions of oven temperature of the column with a variation of $\pm 2^{\circ} \mathrm{C}$; variation of the $\mathrm{pH}$ of the mobile phase varying \pm 0.1 , and change of the flow of the mobile phase $\pm 0.1 \mathrm{~mL}$. Variations in the chromatographic profiles such as retention time, peak chromatographic area, and spectral profile of the samples were monitored. Quantification of the marker in samples of the extract of P. pyramidalis was determined with standard kaempferol in the same analysis condition parameter robustness.

To evaluate the chemical stability in the storage of the standard solutions and FE samples, they were analyzed at time 0 and $24 \mathrm{~h}$ subjected to ambient temperature. To demonstrate the stability, the chromatographic profile, the analysis of the peaks areas, the retention time, and the spectral profile of the marker were verified.

\section{Development of recovery of kaempferol marker}

Pre-treatments were performed to remove interferents. The first step was performed out to remove non-polar compounds with hexane solvent. For the second step, $0.5 \mathrm{~mL}$ aliquot of first stage was reserved, the extract was submitted to liquid-liquid extraction under agitation of tubes, followed by phase separation by centrifugation at $2325 \times$ g (relative centrifugal force) for $10 \mathrm{~min}$. In the evaluation of the kaempferol marker extraction, the sample volume was $1 \mathrm{~mL}$ of the FE.

Three continuous extractions were carried out with dichloromethane, generating in each extraction stage $3 \mathrm{~mL}$ of extractive fraction. An aliquot of $4 \mathrm{~mL}$ of extractive fraction was evaporated at $50^{\circ} \mathrm{C}$. After removal of dichloromethane solvent, the dry fraction was reconstituted in the mobile phase diluent, followed by filtration and injection in the chromatographic system.

\section{Determination of kaempferol content}

The concentration factor was determined according to the successive dilutions made in multiple extraction continued and allowed to quantify the kaempferol content on the extract in $\mu \mathrm{g} / \mathrm{mL}$.

The equation 1 shows how to determine the concentration of the marker in the hydroalcoholic extracts (HAE).

$\mathrm{Ca}=\mathrm{Cp} \times \mathrm{FA} \times \mathrm{Aa} \div \mathrm{Ap}$

Hence:

Ca: Is the concentration of the kaempferol marker in the HAE sample, expressed in $\mu \mathrm{g} / \mathrm{mL}$,

Aa: Is the area of the chromatographic peak marker on HAE,

Ap: Is the kaempferol standard chromatographic peak,

$\mathrm{Cp}$ : Is the concentration of the chemical reference substance kaempferol, FA: Is the analysis factor and is calculated by equation 2 :

$\mathrm{FA}=\mathrm{Ta} \div\{[(\mathrm{Ta} \div \mathrm{Fec}) \times \mathrm{Fevap}] \div$ Vrec $\}$

Hence:

Ta: Is HAE sample taking

Fevap: Is organic fraction aliquot

Fec: Is fraction continuous extraction in 3 batches

Vrec: Is volume of reconstitution in the mobile phase.

Specificity and selectivity assessment.

To demonstrate specificity and selectivity of the method, were performed runs in triplicate with samples of $P$. pyramidalis extract, standard solution and blank of mobile phase. The selectivity of method was evaluated by analyze the retention time characteristic of the marker and was recorded the chromatograms of the extract, kaempferol standard, and blank of the mobile phase, in the range of the UV spectrum from 200 to $600 \mu \mathrm{m}$ in an interval of $20 \mu \mathrm{m}$.

\section{Statistical analysis}

Statistical analysis of the data was determined from using ANOVA analysis of variance in PRISM ${ }^{\circledR} 6.01$ software, considering a significance level $\alpha=0.05$.

\section{RESULTS AND DISCUSSION}

\section{Specificity and selectivity assessment}

Methods described in pharmacopoeias monographs are best suited for quality control and analysis of herbal products; however, there are still no monographs for the species P. pyramidalis [38]. In addition, no chromatographic methodology was validated to quantify the kaempferol marker in hydroalcoholic extracts of $P$. pyramidalis. To validate an analytical methodology, validation parameters should be evaluated and data should be monitored following official guidelines for analytical methods validation. In this work, we follow guidelines of the ICH Q2R8 guide and evaluate: System suitability, specificity, selectivity, sensitivity (limit of detection and quantification), linearity, precision, accuracy (robustness), robustness and stability [37].

The specificity of the method was demonstrated by comparing the chromatograms between a sample of extract, kaempferol standard, and mobile phase blank. Fig. 1 shows that the retention time of kaempferol standard presents is the same of the marker in extract monitored at $17.5 \mathrm{~min}$. The chromatogram of the blank mobile phase indicates that it does neither contain the analyte nor interfering compounds that absorb in the region of 370 nm. Fig. 2 shows that both the extract of $P$. pyramidalis and the kaempferol standard even show similary UV spectra with UVmax at 370 nm and spectral purity equal to 1.

In this work, the specificity of the method assures that the method is specific for the analyte monitored under the described conditions, through the identification and analytical separation, which makes possible the quantification of kaempferol in botanical matrices of the species P. pyramidalis.

To evaluate the selectivity of the method, the dichloromethane fraction of the extract was analyzed, after the sample clean-up process. The results of this run demonstrate that the method is selective for the marker kaempferol indicating that the samples pretreatment in the step with dichloromethane is selective for analysis of polyphenolic compounds, as for marker kaempferol identified at 17.4 min. Fig. 3 shows the chromatographic profile of extract in

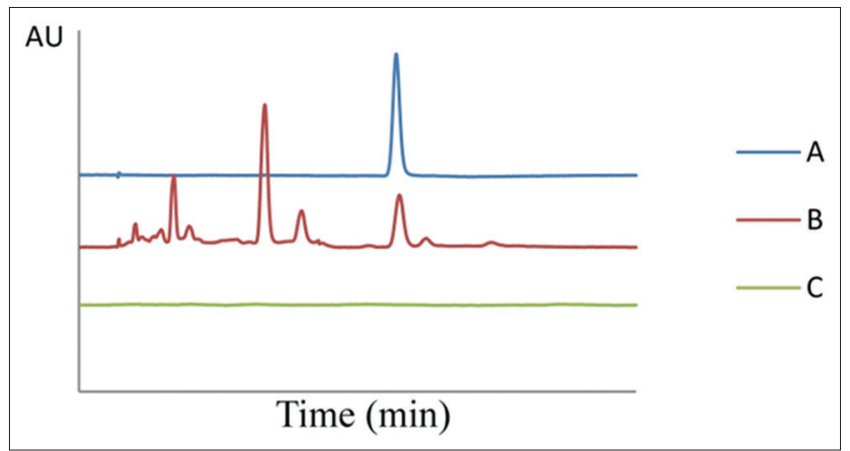

Fig. 1: Chromatograms, (a) peak of standard kaempferol at $\mathbf{1 7 . 4} \mathbf{~ m i n}$, (b) sample Poincianella pyramidalis extract, and (c) blank of mobile phase 


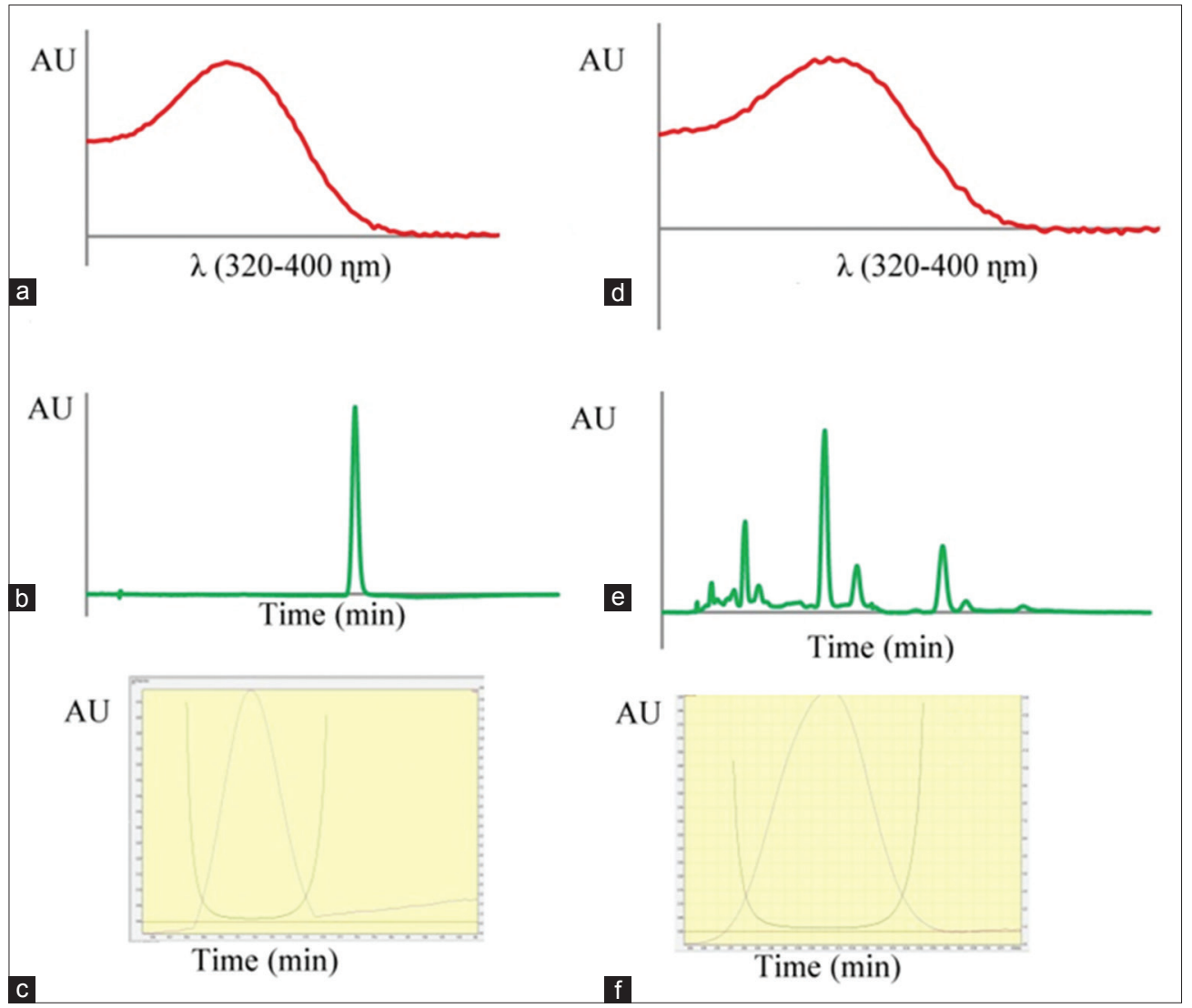

Fig. 2: Ultraviolet spectrum, chromatograms, and peak purity: (a-c) Standard Kaempferol, and (d-f) sample Poincianella pyramidalis extract

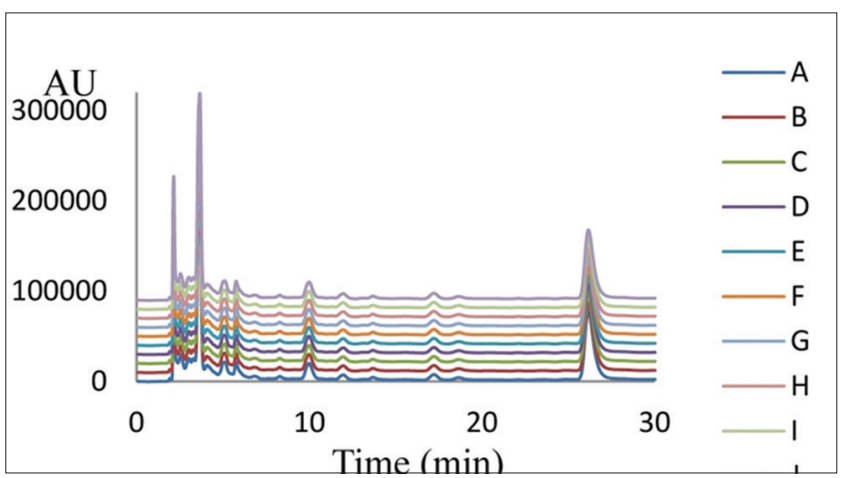

Fig. 3: Chromatogram extract in the range 200-600 $\mathrm{nm}$.

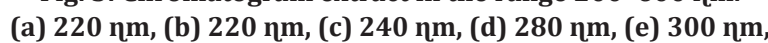

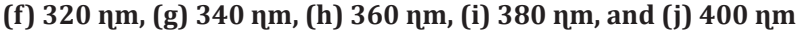

a range of the UV spectrum from 200 to $400 \mathrm{~nm}$ in an interval of 20 пrm.

The selectivity of the proposed method was proved by the excellent chromatographic resolution of the marker peak, by the compatibility of UV spectrum bands between the marker and the kaempferol standard, the absence of interferences around the retention time characteristic of the monitored marker, as well as along the Spectral range of 200 to 400 nm.

The way of approaching selectivity can be confirmed with published works and the results obtained are in agreement with the official guides [37] and by Qiong An and colls. analyzed quercetin by HPLC-DAD in Helleborus thibetanus Franch in the ultraviolet range of 200 to $400 \mathrm{~nm}$ showing the chromatographic profiles in the ultraviolet range to identify absorbance maxima and possible interferents present in the complex matrix [40].

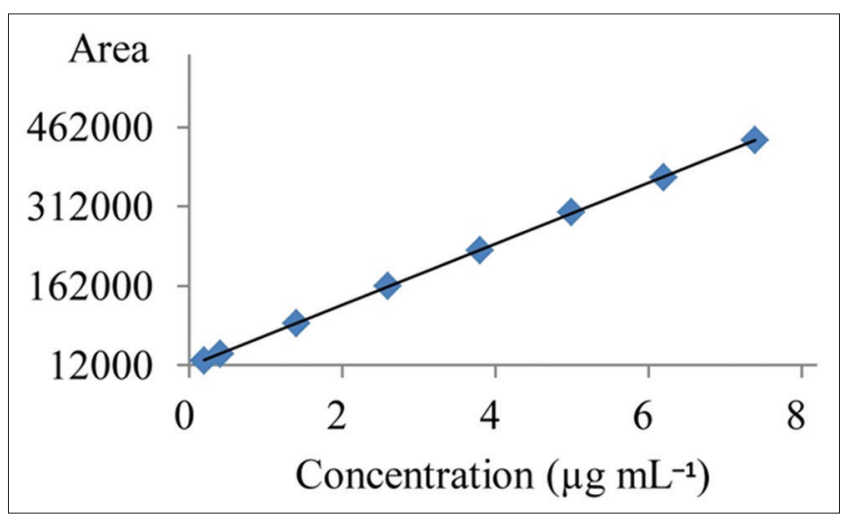

Fig. 4: Data calibration curves of standard kaempferol. Average from three calibration curves with eight concentrations levels

Table 1: Statistical parameters of the linearity

\begin{tabular}{|c|c|c|c|}
\hline Variables & Curve $1^{\mathrm{a}}$ & Curve $2^{b}$ & Curve $3^{c}$ \\
\hline Slope & 59438.7 & 57592.7 & 56132.5 \\
\hline Y-intercept & 4861.7 & 3092.4 & 4921.7 \\
\hline Intercept X & 59438.7 & 57592.7 & 56132.5 \\
\hline 1/Slope & $1.68 \mathrm{E}^{-05}$ & $1.74 \mathrm{E}^{-05}$ & $1.78 \mathrm{E}^{-05}$ \\
\hline Confidence interval & $95 \%$ & & \\
\hline $\mathrm{R}^{2}$ & 0.999 & 1.000 & 0.999 \\
\hline
\end{tabular}

\section{System suitability testing}

The System suitability parameters were evaluated by five replicate injections of the kaempferol standard solution at $4.0 \mu \mathrm{g} / \mathrm{ml}$. The data obtained demonstrate peak area of the reproducible pattern, constant retention time at 17.4 min with variation not greater than $1 \%$. 
Determination of sensitivity

The limit of detection (LOD) is the lowest amount of analyte in the sample, which can be detected but not necessarily quantified as an exact value. The quantification limit (LOQ) is the lowest amount of analyte in the sample, which can be quantitatively determined with suitable precision and accuracy. Both LOD and LOQ were calculated based on the statistical application of linearity data, presenting values of $0.22 \mu \mathrm{g} \mathrm{mL}^{-1}$ for LOD and $0.072 \mu \mathrm{g} \mathrm{mL}^{-1}$ for LOQ

\section{Determination of linearity}

The linearity of the method was evaluated by analyzing the linear regression from three calibration curves with eight concentrations

Table 2: The repeatability and intermediate precision of P. pyramidalis extract

\begin{tabular}{|c|c|c|}
\hline \multicolumn{3}{|l|}{ Repeatability } \\
\hline & $\begin{array}{l}\text { Concentration of } \\
\text { kaempferol }(\mu \mathrm{g} / \mathrm{mL})\end{array}$ & RSD (\%) \\
\hline \multicolumn{3}{|c|}{$\begin{array}{l}\text { Intermediate } \\
\text { precision (intraday) }^{\mathrm{b}}\end{array}$} \\
\hline Day & $18.12 \pm 0.63$ & 0.6 \\
\hline 1 & $17.23 \pm 0.27$ & 1.6 \\
\hline 2 & $17.90 \pm 0.51$ & 2.9 \\
\hline 3 & $18.12 \pm 0.43$ & 2.4 \\
\hline \multicolumn{3}{|c|}{$\begin{array}{l}\text { Intermediate } \\
\text { precision (interday) }^{c}\end{array}$} \\
\hline Average $^{c} \pm$ SD & $17.7 \pm 0.60$ & 3.10 \\
\hline
\end{tabular}

levels. It was demonstrated by the linear regression equation and correlation coefficient $\mathrm{R}^{2}$. The relation between the independent variable (concentration) and the dependent variable (mean area) presented the regression equation $\mathrm{Y}=57721 \mathrm{X}-1010.8, \mathrm{R}^{2}=0.999$ in the range at $0.4-7.6 \mu \mathrm{g} / \mathrm{mL}$. The data of the curve areas, with their respective concentrations, allowed to construct the calibration curve, shown in Figure 4 with correlation coefficient 0.999 . The Table 1 shows the statistical analysis.

The linearity of the method was demonstrated by evaluating the linear correlation $\mathrm{R}^{2}$ coefficient obtained by linear regression and analysis to single factor variance, where it was shown that the $\mathrm{F}$ Tabulated (Critical) is greater than the calculated $\mathrm{F}$ value, for a significance level of $95 \%$. Based on ANOVA, the variations between values obtained from the three curves were not significant.

Blainski and colleagues when validating a method by HPLC-DAD for quantification of gallocatechin and epigallocatechin in Limonium brasiliense rhizomes obtained r]esults of analysis of variance for linearity compatible and consistent with the present work [41].

\section{Precision assessment}

Repeatability and intermediate precision

Repeatability was evaluated using the same analytical parameters, with six chromatographic runs of the extract sample. Intermediate precision was assessed in 3 days with 18 chromatographic runs of the extracted samples for determination of the analyte concentration in the matrix.

Table 3: Evaluate of recovery of the method

\begin{tabular}{|c|c|c|c|}
\hline Level of addition (\%) & Experimental values $(\mu \mathrm{g} / \mathrm{mL})$ & Average of recovery \pm SD & Recovery \% RSD (\%) \\
\hline Low $(20)^{\text {a }}$ & $\begin{array}{l}21.01 \pm 0.26 \\
20.89 \pm 0.47 \\
20.99 \pm 0.22\end{array}$ & $21.0 \pm 0.07$ & $99.7 \pm 0.56$ \\
\hline Medium (100) b & $\begin{array}{l}32.95 \pm 1.61 \\
32.27 \pm 1.35 \\
33.01 \pm 2.44\end{array}$ & $32.7 \pm 0.41$ & $94.9 \pm 1.26$ \\
\hline $\operatorname{High}(180)^{\mathrm{c}}$ & $\begin{array}{l}44.14 \pm 0.62 \\
44.47 \pm 0.45 \\
45.05 \pm 1.09\end{array}$ & $44.6 \pm 0.46$ & $93.0 \pm 1.04$ \\
\hline
\end{tabular}

a-c $\mathrm{n}=18$. SD: Standard deviation, RSD: Relative standard deviation, $\mathrm{n}=$ Number of determinations

Table 4: Evaluation of conditions of column oven temperature, flow of the mobile phase, and pH in robustness of the method

\begin{tabular}{|c|c|c|c|c|c|c|}
\hline \multirow[t]{2}{*}{ Normal condition } & \multicolumn{2}{|c|}{ Temperature $\left({ }^{\circ} \mathrm{C}\right)$} & \multicolumn{2}{|c|}{ Flow (mL/min) } & \multicolumn{2}{|l|}{$\mathbf{p H}$} \\
\hline & 40 & & 1.2 & & 1.6 & \\
\hline Main concentration ${ }^{\mathrm{a}}(\mu \mathrm{g} / \mathrm{mL}) \pm \mathrm{SD}$ & $17.7 \pm 0.5$ & & & & & \\
\hline RSD (\%) & 2.6 & & & & & \\
\hline Tested condition & 38 & 42 & 1.1 & 1.3 & 1.5 & 1.7 \\
\hline Main concentration $^{\mathrm{a}}(\mu \mathrm{g} / \mathrm{mL}) \pm \mathrm{SD}$ & $17.85 \pm 0.3$ & $17.9 \pm 0.3$ & $18.1 \pm 0.4$ & $17.9 \pm 0.3$ & $18.4 \pm 0.5$ & $18.3 \pm 0.4$ \\
\hline RSD (\%) & 1.5 & 1.7 & 2.0 & 1.8 & 2.7 & 2.3 \\
\hline
\end{tabular}

${ }^{\mathrm{a}} \mathrm{n}=6$, SD: Standard deviation, RSD: Relative standard deviation

Table 5: Evaluation of separation efficiency parameters on robustness

\begin{tabular}{|c|c|c|c|c|c|c|c|}
\hline \multicolumn{8}{|c|}{ Tested condition } \\
\hline & \multicolumn{2}{|c|}{ Temperature ${ }^{\circ} \mathrm{C}$} & \multicolumn{2}{|c|}{ Flow $\mathrm{mL} / \mathrm{min}$} & \multicolumn{2}{|l|}{ pH } & \multirow{2}{*}{$\begin{array}{l}\text { Parameter* } \\
\text { Acceptance criteria }\end{array}$} \\
\hline & 38 & 42 & 1.1 & 1.3 & 1.5 & 1.7 & \\
\hline Rs & 2.89 & 2.05 & 2.23 & 2.13 & 2.95 & 2.14 & Rs $>1.5$ \\
\hline $\mathrm{K}^{\prime}$ & 7.76 & 5.85 & 7.7 & 7.08 & 7.12 & 7.08 & $1 \leq \mathrm{K}^{\prime} \leq 10$ \\
\hline $\mathrm{T}$ & 1.09 & 1.07 & 1.07 & 1.05 & 1.05 & 1.06 & $0.5 \leq \mathrm{T} \leq 2$ \\
\hline$\alpha$ & 1.16 & 1.11 & 1.14 & 1.13 & 1.14 & 1.13 & $\alpha>1$ \\
\hline $\mathrm{N}$ & 45239 & 43390 & 46908 & 44167 & 45636 & 44838 & $\mathrm{~N}>2000$ \\
\hline
\end{tabular}

*Rs: Resolution, K': Retention factor, T: Tailing factor, $\alpha$ : Separation efficiency, N: Theoretical plates. Kaempferol peak in normal condition: Temperature $=40^{\circ} \mathrm{C}$,

flow $=1.2 \mathrm{~mL} / \mathrm{min}, \mathrm{pH}=2.5$ to determine the parameter values: $\mathrm{Rs}=2.1, \mathrm{~K}^{\prime}=7.1, \mathrm{~T}=1.1, \alpha=1.1$ and $\mathrm{N}>2000$ 
Table 6: Stability assessment

\begin{tabular}{lll}
\hline & Concentration of kaempferol $(\boldsymbol{\mu g} / \mathbf{m L})$ & \multicolumn{1}{c}{ Stability (24 h after time zero) } \\
\cline { 2 - 3 } & Stability (time zero) & $17.9 \pm 0.6 ;$ \\
Main concentration $^{\mathrm{a}}(\mu \mathrm{g} / \mathrm{mL}) \pm \mathrm{SD} ;$ & $18.12 \pm 0.6 ;$ & 3.2 \\
RSD $(\%)$ & 3.4 & 2 \\
\hline
\end{tabular}

${ }^{a} \mathrm{n}=6$, SD: Standard deviation, RSD: Relative standard deviation. T0: Sample solution in time 0, T24: Sample solution after $24 \mathrm{~h}$ the time 0

In the ANOVA statistical analysis, was not set significant differences between the data considering a level of significance of $95 \%$ and $P$ values greater than 0.05 . Intermediate precision showed a mean concentration value of $17.7 \mu \mathrm{g} \mathrm{mL}^{-1}$ and RSD of $3.1 \%$ as showed in Table 2. These results corroborate with the selectivity data, confirming the precision of the method to analyze fluid extract of $P$. pyramidalis.

Pascale et al. when addressing the precision of the analytical method by gas chromatography to analyze components that cause the greenhouse effect, procedures similar to those carried out in this work were used. The statistical data obtained from both methods meets the requirements of the official guide of the International Conference on Harmonization (ICH) [42]

\section{Accuracy assessment}

The accuracy of the analytical method was assessed by the addition of known quantities of the kaempferol standard in three concentrations: Low, medium, and high. The standard kaempferol addition presents values of $20 \%, 100 \%$, and $180 \%$ in the extract sample for determination of concentration of the analyte in the matrix. Samples were prepared in triplicated and injections in duplicates for each concentration level. Relative standard deviations and recovery capacity were measured.

Table 3 shows the recovery data for the proposed method. It contains the values of mean concentrations obtained for each level of recovery with their respective values of deviations. In the ANOVA statistical analysis, a confidence interval of $95 \%$ was defined, with $\alpha$ level of 0.05 , there was no significant difference in the recovery data set, the $p>0.05$.

Hollands et al. validated an analytical method by HPLC for the determination of procyanidins in apple extracts employing the solvent hexane for the removal of nonpolar compounds such as greases and pigments in the pretreatment of samples. In the evaluation of the recovery, the authors achieved a recovery above $80 \%$ for 4 markers against to a total of 10 monitored peaks. This demonstrates the difficulty of working with complex matrices even after the pretreatment step of samples [43]

\section{Robustness assessment}

The robustness evaluation evaluated the parameters of column oven temperature, mobile phase flow, and mobile phase pH. Samples were prepared in triplicate, and analyzes were performed in duplicates for each condition evaluated.

In the evaluation of the influence of the temperature variations of the column even, in the peaks areas, it was observed that this parameter in the evaluated conditions $\pm 2{ }^{\circ} \mathrm{C}$ did not influence in analysis of marker, indicating that the temperature in the robustness does not influence the analysis. In the evaluation of the influence of the variations in the flow of the mobile phase in analytical results, it was observed that the parameter evaluated did not influence in the conditions of $0.1 \mathrm{~mL}$ in more or less. In the evaluation of the influence of the variations in the $\mathrm{pH}$ of the mobile phase, it was observed that this parameter in the evaluated conditions \pm 0.1 did not influence in the data of the area of the peak analyte. Statistical analysis ANOVA with $95 \%$ confidence intervals had $p>0.05$, showing no significant difference in the set of data. The robustness of the method is shown in Table 4.

Potawale and colleagues, validated a HPLC-DAD method for determination of gimnemagenin, gallic acid and 18- $\beta$-glycyrrhetin acid.
When monitoring the parameter robustness, they changed composition of the mobile phase $( \pm 1 \%)$, phase $\mathrm{pH}( \pm 0.1)$, phase flow and detection wavelength $( \pm 2 \mathrm{~nm})$. The obtained results presented deviation below $2 \%$ for the area of the monitored peaks. As the work cited, the present work investigated possible changes in the proposed method to confirm its robustness, confirming at the end that the method is robust in the conditions analyzed [44]

The robustness of the method was also assessed based on the parameters of the chromatographic separation, evaluating how the temperature, flow, and $\mathrm{pH}$ on limit conditions could interfere in analysis of extracts of $P$. pyramidalis. The analysis of the chromatographic separation parameters, namely, peak resolution (Rs), retention index ( $\left.\mathrm{k}^{\prime}\right)$, tailing factor $(\mathrm{T})$, separation efficiency $(\alpha)$, and theoretical plate numbers $(\mathrm{N})$ was performed in relation to the main peak of kaempferol that was monitored. The results show that the method is robust, with no changes in the separation efficiency of kaempferol in relation to the other peaks of flavonoids, as observed in Table 5 .

\section{Evaluation stability}

The stability of extracted samples was analyzed at time 0 and $24 \mathrm{~h}$. The coefficient of variation of the data and variation of analyte content was determinates. The stability data are plotted in Table 6 . The stability data show that up to $24 \mathrm{~h}$ there was sample stability maintained at room temperature and that the variation obtained was satisfactory.

Unlike other methods, reported in the literature that use acid hydrolysis with heating and high preparation time, the proposed method presents advantages in the application in direct analysis of extracts, being able to be applied in the study of accelerated stability and without degradation due to the heating process, generating more reliable data with better correlation with the long duration data of the confirmatory stability study [45].

These results are according to the minimal official guide requirements $[37,46]$, for methods of validating and demonstrating that the developed method can be suitably used for analysis of kaempferol in the $P$. pyramidalis extract samples.

\section{CONCLUSION}

The development analytical method by HPLC-DAD showing a linear, precise, accurate, and specific for analyte kaempferol in complex matrices of $P$. pyramidalis FE allowed free analysis of interference and selective for the marker may be applied for standardization of extracts and quality control of herbal medicines from P. pyramidalis.

\section{ACKNOWLEDGMENTS}

The authors thank the National Scientific and Technological Development Council (CNPQ) and the Pharmaceutical Studies Development Institute (IDEF) for financial support and the Federal University of Paraíba for supporting the laboratory infrastructure. The authors also thank the researcher Alessandra Vieira Lacerda, for contribution to the botanical identification of the specie.

\section{REFERENCES}

1. Agra MF, Silva KN, Basílio IJ, Freitas PF, Barbosa-Filho JM. Survey of medicinal plants used in the region Northeast of Brazil. Rev Bras Farmacogn 2008;18:472-508. 
2. Bahia MV, Santos JB, David JP, David JM. Biflavonoids and other phenolics from Caesalpiniapyramidalis (Fabaceae). J Braz Chem Soc 2005; 16:1402-5.

3. Alviano WS, Alviano DS, Diniz CG, Antoniolli AR, Alviano CS, Farias LM, et al. In vitro antioxidant potential of medicinal plant extracts and their activities against oral bacteria based on Brazilian folk medicine. Arch Oral Biol 2008;53:545-52.

4. de Albuquerque UP, de Medeiros PM, de Almeida AL, Monteiro JM, de Freitas Lins Neto EM, de Melo JG, et al. Medicinal plants of the caatinga (semi-arid) vegetation of NE Brazil: A quantitative approach. J Ethnopharmacol 2007;114:325-54.

5. Santos AC, Ailane MP, Passos FC, Camargo EA, Estevam CS, Santos MR, et al. Antinociceptive and anti-inflammatory effects of Caesalpiniapyramidalis in rodents. Rev Bras Farmacogn 2011;21:1077-83.

6. Santana DG, Santos CA, Santos AD, Nogueira PC, Thomazzi SM, Estevam CS, et al. Beneficial effects of the ethanol extract of Caesalpinia pyramidalis on the inflammatory response and abdominal hyperalgesia in rats with acute pancreatitis. J Ethnopharmacol 2012;142:445-55.

7. Diniz PB, Ribeiro AR, Estevam CS, Bani CC, Thomazzi SM. Possible mechanisms of action of Caesalpinia pyramidalis against ethanolinduced gastric damage. J Ethnopharmacol 2015;168:79-86

8. Ribeiro AR, Diniz PB, Estevam CS, Pinheiro MS, Albuquerque-Júnior RL, Thomazzi SM. Gastroprotective activity of the ethanol extract from the inner bark of Caesalpinia pyramidalis in rats. J Ethnopharmacol 2013;147:383-8.

9. Bahia MV, David JP, David JM. Occurrence of biflavones in leaves of Caesalpiniapyramidalis specimens. Quim Nova 2010;33:1297-300.

10. Monteiro JM, Lins NE, Amorim EL, Strattmann RR, Araújo EL, Albuquerque UP. Tannin concentration in three simpatric medicinal plants from caatinga vegetation. Rev Arvore 2005;29:999-1005.

11. Devi KP, Malar DS, Nabavi SF, Sureda A, Xiao J, Nabavi SM, et al. Kaempferol and inflammation: From chemistry to medicine. Pharmacol Res 2015;99:1-10.

12. Govindaraghavan S, Sucher NJ. Quality assessment of medicinal herbs and their extracts: Criteria and prerequisites for consistent safety and efficacy of herbal medicines. Epilepsy Behav 2015;52:363-71.

13. Jain HK, Deore DD. Bioanalytical method development and validation for estimation of clopidogrel bisulfate in human plasma by RP-HPLC. Int J Appl Pharm 2016;8:18-21.

14. Tshibangu PT, Kapepula PM, Kapinga MK, Lupona HK, Ngombe NK, Kalenda DT, et al. Finger printing and validation of a LC-DAD method for the analysis of biflavanones in Garcinia kola-based antimalarial improved traditional medicines. J Pharm Biomed Anal 2016;128:382-90

15. Donno D, Mellano MG, Cerutti AK, Beccaro GL. Biomolecules and natural medicine preparations: Analysis of new sources of bioactive compounds from Ribes and Rubus spp. Buds. Pharmaceuticals (Basel)2016;9. pii: E7.

16. Forim RM, Perlatti B, Costa ES, Magnani RF, Souza GD. Concerns and considerations about the quality control of natural products using chromatographic methods. Curr Chromatogr 2015;2:20-31.

17. Migliato KF, Corrêa MA, Salgado HR, Tognolli JO, Sacramento LV, Mello JC, et al. Factorial design of the optimization extraction of Syzygiumcumini (L.) skeels fruits. Quim Nova 2011;34:695-9.

18. Sathe PS, Dighe VV. HPLC METHOD development and validation for quantitation of trigonelline from Mirabilis jalapa Linn. leaves and enhancement in extraction yield from ultra-fine powder. Int $\mathrm{J}$ Curr Pharm Res 2017;9:62-6

19. Nagabi JB, Gurupadayya B. Simultaneous estimation of clopidogrel and atorvastatin in human plasma using bio analytical RP-ultra fast liquid chromatographic. Int J Curr Pharm Res 2015;7:30-5

20. Landim LP, Feitoza GS, da Costa JG. Development and validation of a HPLC method for the quantification of three flavonoids in a crude extract of Dimorphandragardneriana. Rev Bras Farmacogn 2013;23:58-64.

21. Oliveira KB, de Oliveira BH. HPLC/DAD determination of rosmarinic acid in Salvia officinalis: Sample preparation optimization by factorial design. J Braz Chem Soc 2013;24:85-91.

22. $\mathrm{Zu} \mathrm{Y,} \mathrm{Li} \mathrm{C,} \mathrm{Fu} \mathrm{Y,} \mathrm{Zhao} \mathrm{C.} \mathrm{Simultaneous} \mathrm{determination} \mathrm{of} \mathrm{catechin,}$ rutin, quercetin kaempferol and isorhamnetin in the extract of sea buckthorn (Hippophae rhamnoides L.) leaves by RP-HPLC with DAD. J Pharm Biomed Anal 2006;41:714-9.

23. Aparna CH, Madhavi LN, Supriya P, Gowrisankar D. A review on matrix assisted laser desorption/ionization mass spectroscopy. Asian J
Pharm Clin Res 2015;8:28-33.

24. Júnior JO, Costa RM, Teixeira FM, Barbosa WL. Quality Control of Herbal Medicines and Their Derivatives. In: Shoyama Y, editor. Rijeka, Croatia: Intech; 2011, p. 63-81.

25. Matamoros V, Calderón-Preciado D, Domínguez C, Bayona JM. Analytical procedures for the determination of emerging organic contaminants in plant material: A review. Anal Chim Acta 2012; $722: 8-20$

26. Mokhtar M, Russo M, Cacciola F, Donato P. Giuffrida D, Riazi A, et al. Capsaicinoids and Carotenoids in Capsicum annuum L: Optimization of the extraction method, analytical characterization, and evaluation of its biological properties. Food Anal Methods 2016;9:1381-90.

27. Van Beek TA. Chemical analysis of Ginkgo biloba leaves and extracts. J Chromatogr A 2002;967:21-55.

28. Souza VG, Andrade FH, Souza FS, Macedo RO. Analytical method by hplc-dad allows quantification of quercetin marker in standardized extract of Anadenantheracolubrina var. Cebil. Int J Pharm Pharm Sci 2017;9:123-8

29. Liang YZ, Xie P, Chan K. Quality control of herbal medicines. J Chromatogr B Analyt Technol Biomed Life Sci 2004;812:53-70.

30. Ong ES. Extraction methods and chemical standardization of botanicals and herbal preparations. J Chromatogr B Analyt Technol Biomed Life Sci 2004;812:23-33

31. World health organization, et al. Guidelines for good clinical practice (GCP) for trials on pharmaceutical products. WHO Tech Rep Ser 1995;850:97-137.

32. Siddiqui MR, Alothman ZA, Rahman N. Analytical techniques in pharmaceutical analysis: A review. Arabian J Chem 2013;10:1409-21.

31. ICH Q2B. Department of Health and Human Services. Food and Drug Administration. Center for Drug Evaluation Research. Guidance for industry: ICH Q2B Validation of analytical procedures: Methodology. Rockville: ICH Q2B; 1995

32. Monago-Maraña O, de la Peña AM, Galeano-Díaz T. Isocratic LCDAD-FLD method for the determination of flavonoids in paprika samples by using a rapid resolution column and post-column $\mathrm{pH}$ change. Talanta 2016;152:15-22.

33. Naksuriya O, Okonogi S, Schiffelers RM, Hennink WE. Curcumin nanoformulations: A review of pharmaceutical properties and preclinical studies and clinical data related to cancer treatment. Biomaterials 2014; 35:3365-83.

34. Ruperez FJ, Martın D, Herrera E, Barbas C. Chromatographic analysis of $\alpha$-tocopherol and related compounds in various matrices. $\mathrm{J}$ Chromatogr A 2001;935:45-69.

35. Hao Z, Parker B, Knapp M, Yu LL. Simultaneous quantification of $\alpha$-tocopherol and four major carotenoids in botanical materials by normal phase liquid chromatography-atmospheric pressure chemical ionization-tandem mass spectrometry. J Chromatogr A 2005;1094:8390.

36. Salvador IS, Leite RS, Souza VG, Andrade FH, Batista RS, Souza FS, et al. The study of the acute and sub-acute oral toxicities of the nebulized extract of Myracrodruon urundeuva allemao in rabbits. Int $\mathrm{J}$ Pharm Pharm Sci 2017;9:154-60.

37. ICH Q2B. Department of Health and Human Services. Food and Drug Administration. Center for Drug Evaluation Research. Guidance for Industry: ICH Q2B Validation of Analytical Procedures: Methodology. Rockville; 1995.

38. Pandey A, Tripati S. Concept of standardization, extraction and prephytochemical screening strategies for herbal drug. J Pharmacogn Phytochem 2014;2:115-9.

39. El-Didamony AM, Hafeez SM, Saad AA. Extraction-spectrophotometric determination of some antihypertensive drugs in pharmaceutical and biological fluids using two sulphonphthale in dyes. Int J App Pharm 2015;7:10-7

40. An Q, Lu N, Dong Y. Chromatographic fingerprint coupled with hierarchical clustering analysis and principal component analysis for quality evaluation and original discrimination of rhizomes of Helleborus thibetanus franch by HPLC-DAD. Anal Methods 2013:5:5775-84.

41. Blainski A, Antonelli-Ushirobira TM, Godoy G, Leite-Mello EV, Mello JC. Pharmacognostic evaluation, and development and validation of a HPLC-DAD technique for gallocatechin and epigallocatechin in rhizomes from Limonium brasiliense. Rev Bras Farmacogn 2017;27:162-9.

42. Pascale R, Caivano M, Buchicchio A, Mancini IM, Bianco G, Caniani D. Validation of an analytical method for simultaneous high-precision measurements of greenhouse gas emissions from wastewater treatment 
plants using a gas chromatography-barrier discharge detector system. J Chromatogr A 2017;1480:62-9.

43. Hollands WJ, Voorspoels S, Jacobs G, Aaby K, Meisland A, GarciaVillalba $\mathrm{R}$, et al. Development, validation and evaluation of an analytical method for the determination of monomeric and oligomeric procyanidins in apple extracts. J Chromatogr A 2017;1495:46-56.

44. Potawale SE, Pawar PD, Gabhe SY, Mahadik KR. A validated isocratic RP-HPLC method for concurrent estimation of gymnemagenin, gallic acid and 18ß-glycyrrhetinic acid in polyherbal formulation. Int J Pharm Pharm Sci 2014;8:488-92.

45. Monago-Maraña O, de la Peña AM, Galeano-Díaz T. Isocratic LCDAD-FLD method for the determination of flavonoids in paprika samples by using a rapid resolution column and post-column $\mathrm{pH}$ change. Talanta 2016;152:15-22.

46. ANVISA. National Agency for Health vigilance, Pharmacopoeia Brazilian. 5th ed. Brasilia, Brazil: ANVISA; 2010. 